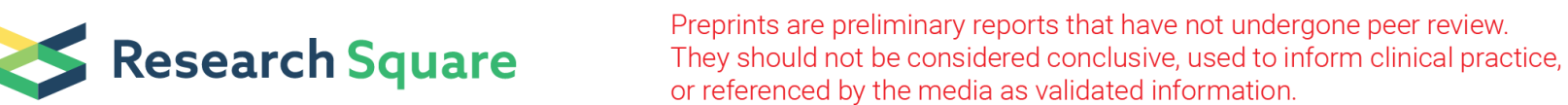

\section{Technology enhanced training in family medicine during Covid-19 pandemic, trainers and trainees' view}

\section{Marwa Mostafa Ahmed}

Cairo University, Kasralainy faculty of medicine

Inas Talaat El Sayed

Cairo University, Kasralainy faculty of medicine

Samar Fares ( $\square$ samar.fares@kasralainy.edu.eg)

Cairo University, Kasralainy faculty of medicine https://orcid.org/0000-0002-3438-1329

\section{Research Article}

Keywords: Medical Education \& Training, Family Medicine, Technology Enhanced Training, Covid 19.

Posted Date: August 17th, 2020

DOI: https://doi.org/10.21203/rs.3.rs-55741/v1

License: (c) (i) This work is licensed under a Creative Commons Attribution 4.0 International License.

Read Full License 


\section{Abstract}

Purpose of the study: how to shift from face-to-face clinical training into technology enhanced training during Covid 19 pandemic.

Study design: Online trainer simulation with pre-prepared case scenarios and case discussion was our designed interventional training using Zoom application.

Results: Regarding trainee's feedback to the zoom training, $85 \%$ of them thought that it was useful. More than $75 \%$ of them recommended this online training for future trainees. More than $80 \%$ of the trainers were satisfied with the online training experience. More than $75 \%$ of them thought that this was a beneficial experience for the participating house officers. Although two-third of the trainers perceived the training to be mildly and moderately overloading, yet more than $80 \%$ of them were satisfied with this training experience and about three-fourth of them preferred it on face-to-face training. They suggested increasing the time of the session to allow for more feedback and discussion.

Conclusion: Technology enhanced training is a good way of training that can improve many aspects of clinical family medicine skills as communication skills, patient-centred approach, clinical reasoning, and construction of management plan. It can be applied in other specialties especially in crisis times. In the future, it can be used as blended method of training beside face to face training in the clinics so they can complement each other.

\section{Introduction}

The Covid-19 pandemic has a dramatic effect on health professions education and training worldwide. As a result of the forced closure of medical schools, teaching had to be delivered remotely instead of face-to-face. Clinical skills training poses an important challenge for medical educators. An important part of the students and residents training are usually spent in different outpatient clinics and hospitals wards to acquire competency in clinical skills. Because student's safety is a top priority for all medical schools, this cannot be fulfilled nowadays.[1]

Many solutions have been proposed including postponing clinical training until the end of Covid-19 pandemic to decrease the risk of exposure for medical students. Some medical schools started to use videos to demonstrate procedural skills. But students' feedback revealed that using online videos alone was not enough to learn the required clinical skills and they are still in need for faculty teaching [2]. Virtual patients were also used to train students in clinical skills. Although they offered a good opportunity to train students on clinical reasoning, still it is not enough alone and should be integrated with structured tutor sessions.[3]

Using technology to find a solution for clinical training was of utmost importance to avoid clerkships cancellation and at the same time allow students to improve their skills and adaptability. Technologyenhanced training (TET) helps in developing the trainees required clinical and interprofessional skills in 
an innovative matter. Trainees who are capable of adapting to this new method of training will have the ability to adapt to any educational or professional crisis later.[4]

Maintaining the training program of the house officers and residents in family medicine department during Covid-19 pandemic was a challenge, The clinics' work of the house officers had to be reduced to keep the safety of the doctors and patients through reducing the clinics' crowdedness and keeping the physical distancing. So, it was mandatory to find an alternative way of training and at the same time preserving the training quality. Technology-enhanced training enables training on communication skills, clinical reasoning and how to construct an evidence-based management plan, which represents an important pillar in family medicine training. In this work, we will describe our experience in shifting from face-to-face training into technology-enhanced training over a short period. We will also present the feedback of the trainers and trainees to this new experience of technology-enhanced training in family medicine.

\section{Materials And Methods}

Online trainer-simulation pre-prepared case scenarios followed by discussion, was our chosen solution during the current crisis. Technology-enhanced training was planned using Zoom meeting application. The proposed training plan of TET was presented to the department council and an approval was obtained. This was followed by constructing a detailed plan with the expected timeline and obtaining the approval of the department's research committee.

The proposed plan consists of two phases as follow:

\section{Preparatory phase}

This phase started by assigning the training team from the department's lecturers and assistant lecturers (trainers) and residents (organizers and trainers).

Cases scenarios preparation (with role player instructions and scientific background attached), and roleplay training of the team were the next steps in this phase, which were semi-ready as training using simulation and role-play with discussions was part of the conventional training in the family medicine department.

The next very crucial step was to train the trainers, organizers and house officers on the use of the application that will be used in the training program, Zoom meeting application with the option of breakout rooms was the chosen application for online family medicine training. Because it is freely available on the web with no need for an official or institutional account, also its free basic package was enough for us to implement our training with no need to subscribe to the premium version. Technology training included 3 educational videos produced by the IT committee of the department (consists of lecturer and an assistant professor). The videos explained in detail how to download, sign in, host, and join a meeting. Also, how to use the break-out room option of the Zoom meeting application with an average length of 
10-15 minutes. Then several Zoom meetings were held with the use of break out rooms to get familiar with the application.

The last step of this phase was dividing the current cohort of house officers into 5 groups and each organizing resident was responsible for a group of house officers. Each organizer continuously communicated with his assigned group through a WhatsApp group to address any inquiries and to provide them with the 3 educational videos to ensure they were trained on the used technology too.

\section{Work phase}

\section{Step 1}

The previously designed family medicine online training via role-playing and cases discussion using Zoom application and break out rooms were applied to the current cohort of house officers ( 50 house officers). The team organized several simultaneous Zoom meetings where the house officers were distributed over the trainers' rooms, then shifted to another breakout room after finishing the discussion. In the same zoom meeting, each house officer was trained on several case scenarios with different trainers in the presence of residents as observers of the training.

The virtual training sessions were conducted in a systematic order (Figure 1). During the sessions, the trainers showed special interest to conduct of the interview, patient's hidden agenda, ICE (ideas, concerns, and expectations) of the patient and the importance of adopting the biopsychosocial approach.

After this training experience, the feedback was obtained from the house officers and trainers. Although the house officers' feedback was positive, $83 \%$ of the trainers prefer to work individually with their assigned group of house officers and they felt that there was no need to work simultaneously and use break out rooms.

\section{Step 2}

After the next cohort of house officers ( 49 house officers) joined family medicine training, we made some modifications on the training program guided by the tutor's feedback while keeping the main core of the training. The joined group was divided into 5 groups, each group has its responsible lecturer, assistant lecturer and resident. Each group had 2 weekly Zoom online meetings to get trained on the cases scenarios through role-play and discussions which enables us to provide more case scenarios but at a more eased pace to avoid burdening our trainers. At the end of the family medicine rotation, each house officer completed 4 online training sessions.

All participants of the training program including the training team and house officers consented on recording the training sessions. This allows for having a repository of videos of the recorded sessions and this will be used in building an online family medicine training bank, for future training of house officers and even undergraduate training. 
It was difficult to assess the house officers' feedback regarding what they preferred and what was more useful for them from the 2 tried methods (one zoom meeting with multiple case scenarios or multiple online meetings) because each step was performed on a different cohort of house officers.

\section{Step 3}

Structured trainers and house officers feedback form was designed and sent to all the participants, as feedback is crucial to enable us to continuously improve our training.

\section{Results}

\section{House officers' feedback}

Forty-seven house officers respond to the survey ( $94 \%$ response rate). Regarding their feedback to the zoom training, $85 \%$ of them thought that it was useful. Figure 2 shows their feedback regarding different aspects of online training. More than $75 \%$ of them recommended this online training for future trainees, while only one of them did not recommend it. Their feedback included 'a very nice experience, need to be repeated more often, we appreciate spending this great effort to continue our training in the department, well-organized training, although TET is not as good as dealing with real patients in the clinics it was informative and beneficial.

\section{Trainers feedback}

More than $80 \%$ of the trainers were satisfied with the online training experience (figure 3 ). More than $75 \%$ of them thought that this was a beneficial experience for the participating house officers. Regarding the workload, one-third of the trainers perceived the online training to be moderately overloading while another third of them thought it is mildly overloading (figure 4). Surprisingly, $75 \%$ of them preferred online house officers training on face-to-face training.

They stated that it was a great experience for them, especially the residents as they became more confident with their teaching skills. One of the trainers stated that 'I think it was really good to experience something new and to find a way to communicate with the house officers during this period of social distancing. It was helpful for them to understand more about family medicine as best we can without them being in the clinic'. Another one stated that 'online training is informative, to the point and beneficial to the tutor and house officer'.

They suggested increasing the time of the session to allow for more feedback and discussion.

\section{Discussion}

The real challenge in our TET experience during Covid-19 pandemic was not changing the mode of delivering family medicine training from face to face to online, the real challenge was creating a 
supportive culture for the adoption of this innovative experience, which requires different skills and competences from the trainers and trainees, and at the same time maintaining the quality of training.

Before adopting any new method of training, the obstacles and challenges should be addressed. This was the situation in preparing the plan for TET in our department and a proposed solution was designed to maintain the quality of the training. One of the most important obstacles was limited resources. We overcame this, by using a free application (zoom meeting application) and to avoid the extra cost of role players, trainer-simulation was adopted where the trainer plays the role of the patient.

Taylor et al in 2020 stated that to engage students in a learning experience during Covid-19 9crisis, multiple conditions should be fulfilled; ensuring the ability of the tutor to get used to this novel method, using the available training resources, and maintaining constructive feedback and mentorship in a virtual environment. And to ensure that the trainees have the opportunity to continuously practice what they have learned. In the application of TET, online training was done to ensure that the trainers and trainees are familiar with the use of zoom meeting applications before the start of the training. We used the same case scenarios that we used before in face-to-face learning but after applying some modifications to be more engaging and challenging to suit the online environment. Continuous feedback and reflection were done during the training sessions and all through their rotation through WhatsApp groups. TET sessions were trainee-centred training, every session let the trainee practise what was learned in the previous session putting into consideration the feedback of his performance in the previous sessions. This was done through having a feedback form for every trainee which is shared among his trainers through shared google folder.

Trainer-simulation was found to be an effective method of clinical training. In agreement with (Dalwood et al., 2020), that concluded that peer simulation appears to be a good method of providing clinical skills training in clinical skills for students, it encourages student self-confidence and efficacy, it also improves communication and patient empathy.

Successful distance learning requires dedicated proper preparation of both trainers and trainees and close contact of each trainer and trainee to deal properly with their feedback. This is similar to Torre et al (2020) who concluded that Feedback on learning is an essential component.

Regarding the Trainees feedback, more than three-fourth of them recommended this training for future trainees, this is similar to a cross-sectional study conducted by Sajida et al., in 2015 in Saudi Arabia that revealed that the overall satisfaction scores with simulation-based learning were high (85\%). The trainees were appreciating the effort spent to rapidly transform face-to-face training into TET in a short duration. And although they missed their interaction with real patients in the family medicine clinics, they still find TET to be beneficial.

Although two-third of the trainers perceived the training to be mildly and moderately overloading, yet more than $80 \%$ of them were satisfied with this training experience and about three-fourth of them preferred it on face-to-face training. As Taylor et al in 2020 highlighted, consistent changes can be easily achieved 
with the presence of "local champions who are active teachers". This was the cornerstone of our TET, having dedicated trainers, who didn't mind spending efforts in this challenging situation to ensure highquality house officer training.

Future work

This training experience with its positive feedback from trainers and trainees and its learned lessons will be used as a pilot study to implement the training on family medicine residency level. Also, our residents will have more active roles in future training of house officers as their participation in this experience has made them more confident with their teaching skills. And this will motivate them to participate more actively in the next training sessions. Our plans also include the use of the recorded training videos for future training of house officers and even to be included in the undergraduate training.

\section{Conclusion}

Technology-enhanced training is a good way of training instead of face to face training especially that it can be used to improve many aspects of clinical family medicine skills such as communication skills, patient-centred approach, clinical reasoning and construction of management plan. It can be applied in other clinical specialities especially in crisis times.

Although the feedback from both Trainer and trainee so far has been overwhelmingly positive, some have expressed understandable concern about the lack of opportunity to practice clinical examination skills in the clinics. So, in the future, it can be used as a blended method of training besides face to face training in the clinics so they can complement each other.

\section{Abbreviations}

ICE: ideas, concerns, and expectations.

TET: Technology enhanced training.

\section{Declarations}

\section{Availability of data and materials}

All data generated or analysed during this study are included in this published article [and its supplementary information files].

\section{Competing interests}

All authors state that there is not any competing interest with any institute or company.

\section{Funding}


No Fund was needed in this work.

\section{Authors' contributions}

In preparatory phase, IE was responsible for case scenarios' preparation, MA and SF managed technology training. All authors participated in the training process and manuscript writing. IE revised the manuscript for grammar pitfalls, SF submitted it and MA was responsible for the overall content and quality.

\section{Acknowledgements}

The authors want to express their gratitude to all the training team of lecturers, assistant lecturers and residents of the family medicine department, Cairo University. Also, to all the participating house officers for their motivation to try a new experience and for their time and efforts.

\section{References}

1. Goh, P.-S., \& Sandars, J. (2020). A vision of the use of technology in medical education after the COVID-19 pandemic. MedEdPublish, 9(1). doi: 10.15694/mep.2020.000049.1.

2. Sobocan, M., \& Klemenc-Ketis, Z. (2015). Family medicine education with virtual patients: A qualitative study. Acta Informatica Medica, 23(4), 202-205. doi: 10.5455/aim.2015.23.202-205.

3. Jang, H. W., \& Kim, K. J. (2014). Use of online clinical videos for clinical skills training for medical students: Benefits and challenges. BMC Medical Education, 14(1). doi: 10.1186/1472-6920-14-56.

4. Ferrel, M. N., \& Ryan, J. J. (2020). The Impact of COVID-19 on Medical Education. Cureus. doi: $10.7759 /$ cureus.7492.

5. Taylor, D., Grant, J., Hamdy, H., et al. (2020). Transformation to learning from a distance. MedEdPublish, 9(1). doi: 10.15694/mep.2020.000076.1.

6. Dalwood, N., Bowles, K., Williams, C, et al. (2020). Students as patients: A systematic review of peer simulation in health care professional education. Medical Education, 54(5), 387-399. doi: 10.1111/medu.14058.

7. Torre, D. M., Schuwirth, L. and Van der Vleuten, C. (2020) 'Theoretical considerations on programmatic assessment'. Medical Teacher. 42(2), 213-220. doi:

10.1080/0142159X.2019.1672863.

8. Sajida Agha, Asma Y. Alhamrani, and Muhammad A. Khan, (2015) Satisfaction of medical students with simulation based learning. Saudi Med J. 36(6): 731-736. doi: 10.15537/smj.2015.6.11501.

\section{Figures}


- Other relevant symptoms.

- Differential Diagnosis

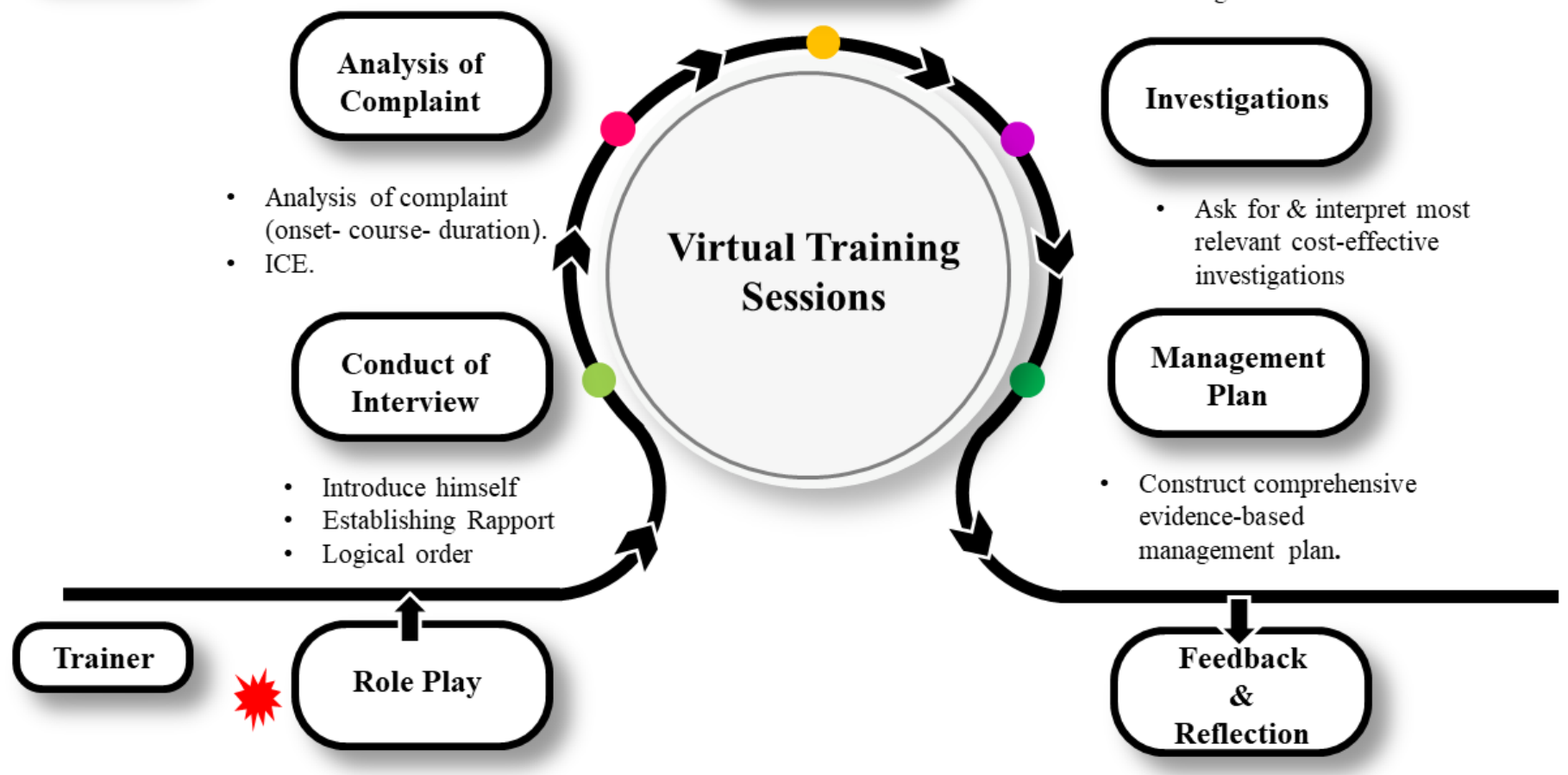

\section{Figure 1}

The process of the virtual training sessions

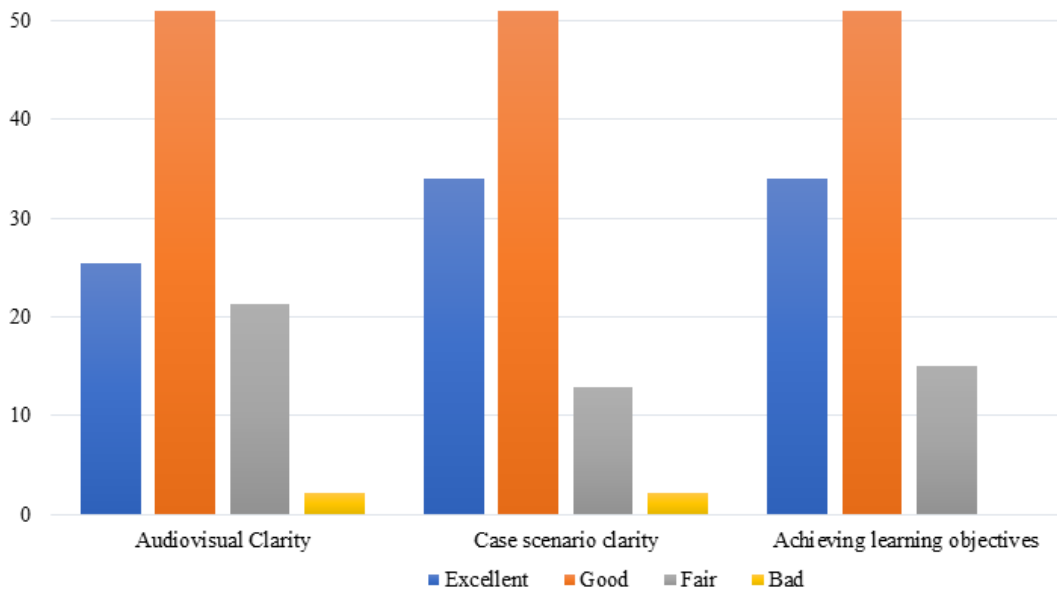


Figure 2

House officers' feedback regarding different aspects of the online training

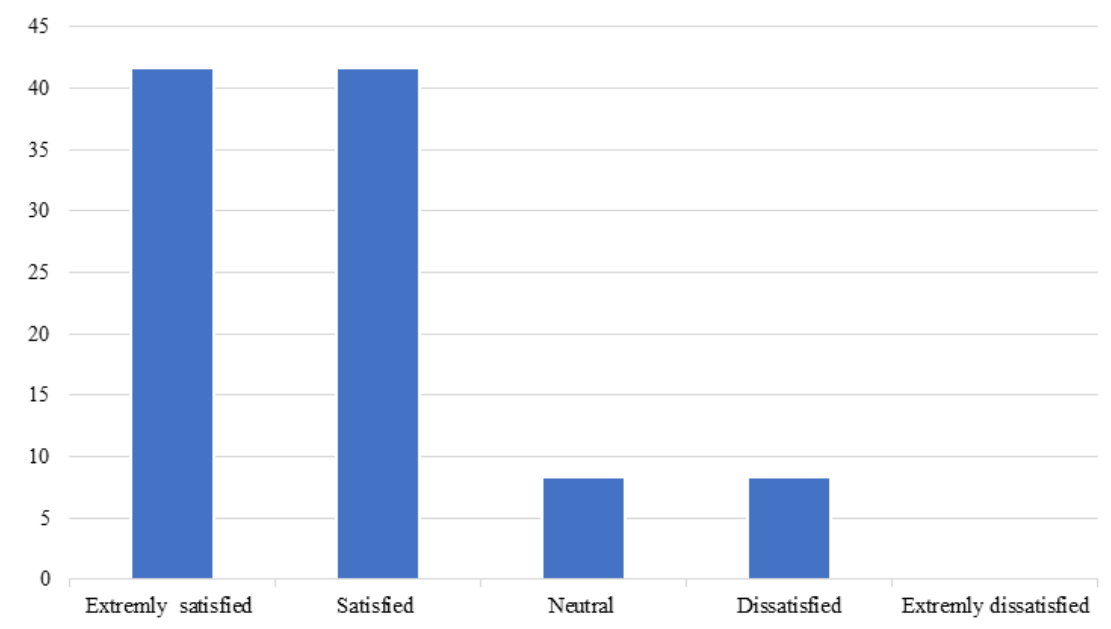

Figure 3

Overall satisfaction of the trainers 


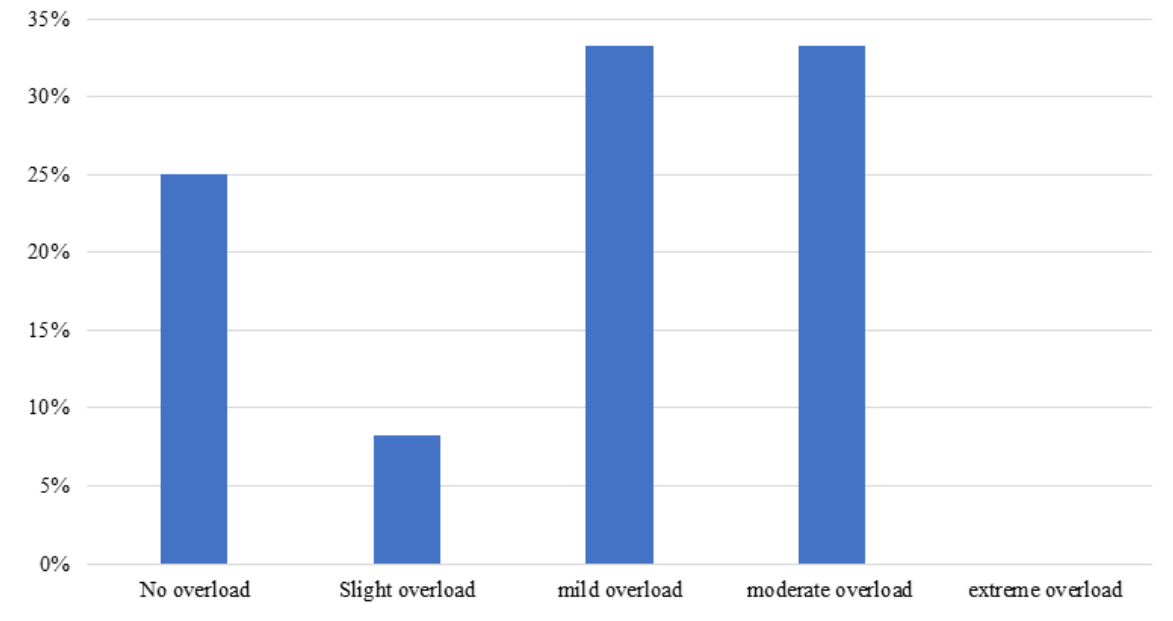

Figure 4

Perceived workload of the trainers 